\title{
Employment of damage plasticity constitutive model for concrete members subjected to high strain-rate
}

\author{
Mohammed J. Altaee ${ }^{1}$, Majid M.A. Kadhim ${ }^{2}$, Sarmed S. Altayee ${ }^{3}$ and Ali H. Adheem ${ }^{4}$ \\ \{mohammed.altaee@uobabylon.edu.iq1,eng.majid.mohammed@uobabylon.edu.iq2, \\ eng.sarmed@gmail.com3,inkr.ali@atu.edu.iq4\} \\ ${ }^{1}$ Environmental Researches and Studies Centre, University of Babylon, Hilla, Iraq \\ ${ }^{2,3}$ College of Engineering, University of Babylon, Hilla, Iraq \\ ${ }^{4}$ Kerbala Technical Institute, Al-Furat Al-Awsat Technical University, 56001 Kerbala, Iraq
}

\begin{abstract}
Concrete damage plasticity (CDP) model is used to model the concrete damage through using ABAQUS software. Among several input parameters that should be defined in CDP model, the dilation angle $(\psi)$, eccentricity parameter and tensile behaviour, have been identified as a significant influence on the finite element (FE) results for concrete modelling under static loading while limited studies examined these parameters for concrete subjected to impact load and high-strain rate. This study aims to focus on numerical modelling of impact-loaded concrete, examine and calibrate the above CDP model parameters using three-dimensional FE modelling. Several values of dilation angles, $\psi$, of 30 to $55^{\circ}$ and eccentricity parameter of 0.1 to 0.2 have been used to capture the test behaviour. The model tensile softening behaviour was also investigated using three models, bilinear stress-strain, tri-linear stress-strain and stress-crack opening displacement. The FE results revealed that the value of dilation angle ranged $45-50^{\circ}$, the eccentricity parameter and tri-linear stress-strain model of tensile softening provided better correlations with test results in terms of displacement-time plots and cracking paths.
\end{abstract}

Keywords: concrete damage plasticity, finite element, ABAQUS, strain-rate

\section{Introduction}

Civil, ocean engineering and preventive engineering use the reinforced concrete (RC) widely in different structural elements. Many theoretical methods frequently used to study the behaviour of concrete structures exposed to shock loads to avoid the big difficulties in practical tests under such loads. The modern technology of computers, 3D FE codes, provides a numerical simulation to predict the impact performance of RC structures. In addition, the numerical model uses very simple concrete models to demonstrate the complex behaviour of the concrete structure. However, the post-peak softening response cannot be captured using Drucker-Prager and Von-Mises Models in the simulation of RC girder under impact loading[1-2]. Also, these difficulties present in the case of using the bilinear model on the compression side together with a tension cut-off to simulate the nonlinear dynamic response of RC girders [3],[4]. Moreover, the concrete damage model cannot be predicted in elastic volume expansion for concrete columns under transverse impact [5]. Othman and Marzouk [6] were successfully used the plasticity constitutive model to achieve high-performance under dynamic loading rates. Shabbar et al [7] employed also the CDP in modelling the damage of aerated concrete under axial load. From the above, it appears that there is no study on damage plasticity constitutive model for normal concrete under impact load. 
The current research aims to verify the simulation of the numerical model with the concrete experimental model, which includes strain rate and reinforcement effects, to study the effect of these factors on the performance of RC beams subjected to impact loads. In this current study, the commercial tool ABAQUS was employed out to simulate the experiments that have been conducted for RC beams under impact loads.

\section{Experiment description}

To validate the numerical model, a practical study was chosen from the literature. The study carried out by Fujikake et al [8] was used. The RC beam specimens have 250 x $150 \mathrm{~mm}$ crosssection and a length of $1700 \mathrm{~mm}$ as shown in Fig.1. The beams were reinforced with three various longitudinal reinforcement scenarios consisted of two bars with a diameter of 13,16 and $22 \mathrm{~mm}$ with a yield strength of 397, 426 and $418 \mathrm{MPa}$ respectively while the shear reinforcement was with $10 \mathrm{~mm}$ bars having a yield strength of $295 \mathrm{MPa}$ distributed every $75 \mathrm{~mm}$ as shown in

Fig. 1. The strength for concrete compressive was $42.0 \mathrm{MPa}$. In order to perform the influence of the loading test, a drop hammer machine was used. A $400 \mathrm{~kg}$ impactor was dropped freely onto the top surface of the RC beam at mid-span from four different heights: $0.15,0.3$, 0.6 , and $1.2 \mathrm{~m}$ for series S1616 beam specimens; 0.3, 0.6, 1.2, and $2.4 \mathrm{~m}$ for other series (S1322 and S2222). The numeric values in the naming system used in this experiment were denoted for the diameter of bars used as compression and tension reinforcement respectively. For example, S1322 means that two bars of $13 \mathrm{~mm}$ diameter and two bars of $22 \mathrm{~mm}$ diameters were positioned in the top and bottom of the beam's cross-section respectively. In total 4 samples for each reinforcement, scheme were tested and will be used to validate the numerical model.

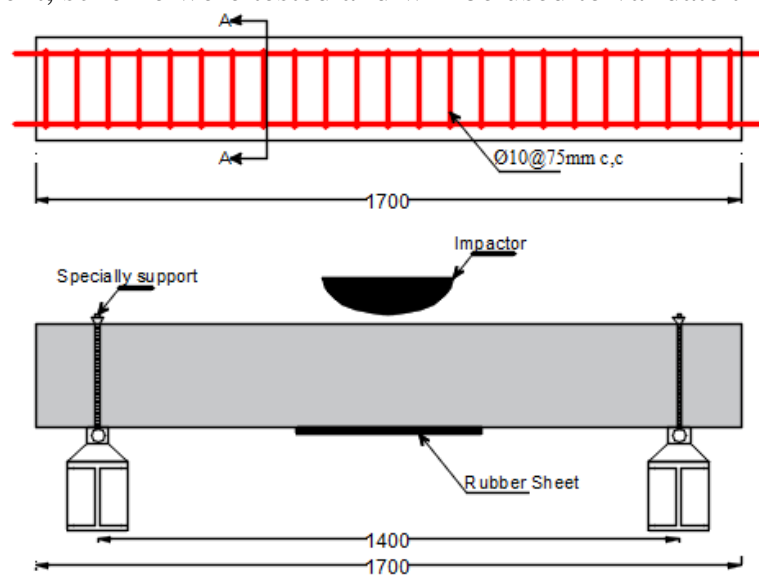

Fig. 1 Details of the tested RC beams.

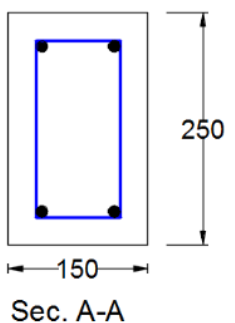

Sec. A-A

\section{Concrete damage plasticity}

Lubliner et al. [9] introduced firstly the model of concrete damage plasticity (CDP), Bacelona model, for monotonic loading. CDP model was modified later by Lee and Fenves [10] to consider the cyclic and dynamic loadings. In this model, CDP model, the stress plan is not a 
circle which is governed by the shape parameter $(\mathrm{Kc})$, see Fig. 2-a.This parameter, Kc, represents the constant of second stress for tension and compression ratio at the same hydrostatic stress and must be $0.5 \leq \mathrm{Kc} \leq 1$ (default $\mathrm{Kc}$ value is $2 / 3$ ). The stress ratio, the ratio of biaxial to uniaxial compressive strengths $\sigma b o / \sigma c o$, should be defined in CDP ( $\sigma b o / \sigma c o=1.16$ as default based on Kupfer's curve) [11].

Since the concrete is a granular material, it is susceptible to volumetric strain generated during plastic deformation when it is subjected to shear deformations [12]. The potential plastic flow of concrete material in CDP used two input parameters, $(\psi)$, and $(\epsilon)$ as shown in Fig. 2-b. Due to the dilation angle's value is in the range of $5^{\circ}$ to $42^{\circ}$ for traditional concrete [13], [14], [15], [16], [17], [18], this study focuses on the sensitivity of this parameter and its relation with steel reinforcement ratio.

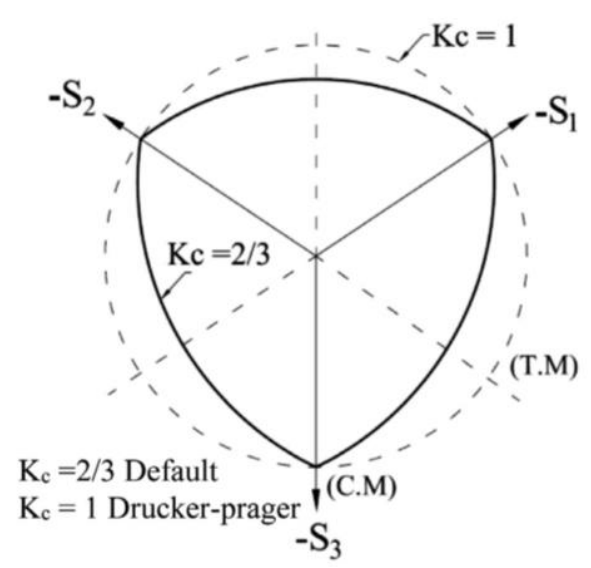

(a)

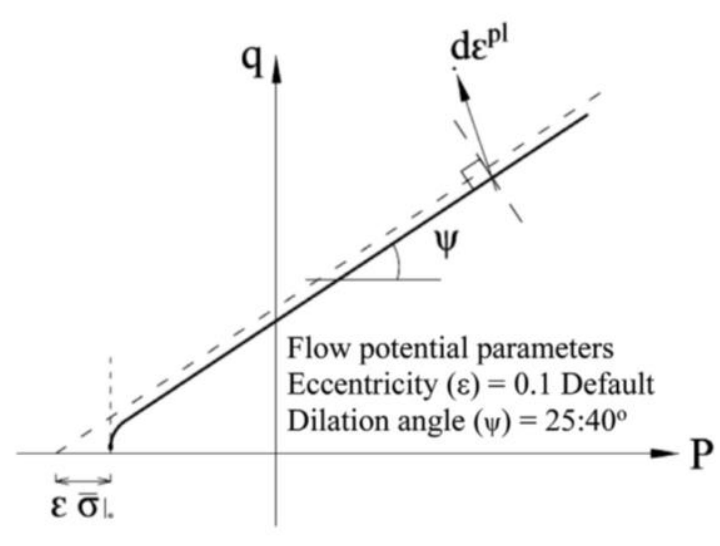

(b)

Fig. 2 CDP's (a) yield surface and (b) flow rule.

\section{Finite element modelling}

\subsection{Element selection}

The models build up using ABAQUS software with the explicit solver. The concrete volume was modelled with $5 \mathrm{~mm}$ mesh for an 8-node brick element (C3D8R). The steel reinforcement (longitudinal and stirrups) was modelled using the two-node linear displacement truss element (T3D2). A discrete rigid models was applied to represent the impactor.

\subsection{Materials modelling}

Concrete in compression. The confined concrete in compression with rectangular hoop confinement is widely modelled using the proposed model by Kent and Park [19]. The curve of this model, shown in $\mathrm{F}$

Fig. 3, consists of three parts with the stress of $0.5 f_{c}^{\prime}$ [region $\mathrm{AB}$ in $\mathrm{F}$

Fig. 3]. The concrete stress (fc) in the following region [region $\mathrm{BC}$ in $\mathrm{F}$

Fig. 3] is related to the concrete strain $(\varepsilon c)$ by Eq. (1): 


$$
f_{c}=f_{c}^{\prime}\left(2\left(\frac{\varepsilon_{c}}{\varepsilon_{o}}\right)-\left(\frac{\varepsilon_{c}}{\varepsilon_{o}}\right)^{2}\right)
$$

Where $\mathrm{fc}^{\prime}$ is the concrete strength and $\varepsilon 0$ is the strain at $\mathrm{fc}^{\prime}$ which can be calculated as $\varepsilon_{0}=$ $\frac{2 f_{c}^{\prime}}{E_{c}}[20]$, in which, Ec, is determined from ACI 318-14 [21] as $\left[E_{c}=4700 \sqrt{f_{c}^{\prime}}\right]$. For region CD in the last part [i.e. at $\varepsilon_{o} \leq \varepsilon_{c} \leq \varepsilon_{20 c}$ ], the $f_{c}^{\prime}-\varepsilon_{c}$ relation is linear, and from $\mathrm{F}$ Fig. 3 the confinement ratio, depends on the stirrup details as explained below:

$$
\begin{gathered}
f_{c}=f_{c}^{\prime}\left(1-Z\left(\varepsilon_{c}-\varepsilon_{o}\right)\right) \\
Z=\frac{0.5}{\varepsilon_{50 u}+\varepsilon_{50 h^{-}-\varepsilon_{c o}}} \\
\varepsilon_{50 u}=\frac{30+0.29 f_{c}^{\prime}}{145 f_{c}^{\prime}-1000} \\
\varepsilon_{50 h}=\frac{3}{4} \rho^{\prime \prime} \sqrt{\frac{b^{\prime \prime}}{S}} \\
\rho^{\prime \prime}=\frac{2\left(b^{\prime \prime}+d^{\prime \prime}\right) A_{s}^{\prime \prime}}{b^{\prime \prime} d^{\prime \prime} S}
\end{gathered}
$$

where, $A_{s}^{\prime \prime}$ is the cross-sectional area of the hoop bar and $S$ is the distance between the centers of the hoops. The width and depth of the confined core are $b^{\prime \prime}$ and $d^{\prime \prime}$ respectively

Concrete in tension: ABAQUS provides three different approaches to model the concrete damage in tension in which the input values are the tensile strength in addition to strain, crack opening displacement or fracture energy. Four models were evaluated in this work.

Model I

For this model, the tensile stress was increased linearly with the strain till the concrete cracked. Lately, tensile stress linearly decreases to zero as shown in

Fig. 4. For zero stress, the strain is 50 times the strain at failure, $50 \varepsilon_{c r}$.

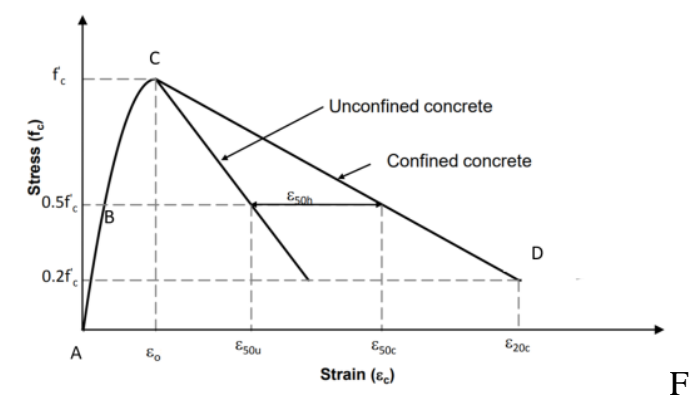

Fig. 3 Compression stress-strain model for confined and unconfined concrete [19] 


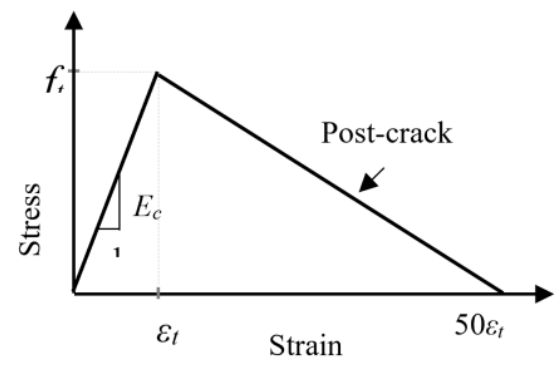

Fig. 4 Proposed stress-strain of a model I in tension [21]

\section{Model II}

As in model I, the tensile stress-strain graph was increased linearly to crack the concrete but two descending portions of the tensile stress-strain graph have accurately captured the response caused by primary and secondary cracking phenomena as shown in Fig. 5. The strain at zero stress can be considered 10 times the strain at failure, $10 \varepsilon_{c r}$.

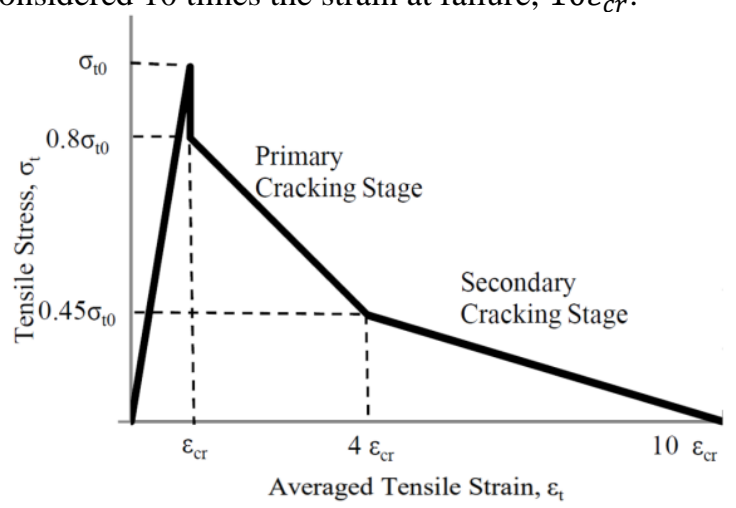

Fig. 5 Proposed stress-strain of model II in tension [22]

Model III

The stress-crack opening displacement relationship was used in this model; the following is the equations of Tao and Chen [23]:

$$
\begin{aligned}
& \mathrm{w}_{c r}=5.14 \frac{G_{F}}{f_{t}} \\
& f_{t}=1.4\left(\frac{f_{c}^{\prime}-8}{10}\right)^{2 / 3} \\
& G_{F}=\left(0.0469 d_{a}^{2}-0.5 d_{a}+26\right)\left(\frac{f_{c}^{\prime}}{10}\right)^{0.7}
\end{aligned}
$$

where $d_{a}$ is the maximum aggregate size of the concrete.

Model IV

The fracture energy was used in this model which can be obtained from equation (10) CEB-FIP[24].

$$
G_{F}=G_{F 0}\left(\frac{f^{\prime}{ }_{c}}{f^{\prime}{ }_{c o}}\right)^{0.7}
$$


Where $G_{F 0}$ is the base value of fracture energy which can be obtained from Table 1 depending on maximum aggregate size and the value of $f^{\prime}{ }_{c o}$ is equal to $10 \mathrm{MPa}$ as sets by CEBFIP[24].

Table 1. Base values of fracture energy $(\mathrm{Nmm} / \mathrm{mm} 2)$ [24].

\begin{tabular}{ll}
\hline Maximum aggregate size, $d_{a}(\mathrm{~mm})$ & Fracture energy, $G_{F}(\mathrm{Nmm} / \mathrm{mm} 2)$ \\
\hline 8 & 0.025 \\
16 & 0.030 \\
32 & 0.058 \\
\hline
\end{tabular}
as follows:

Strain rate effect can be calculated using the proposed results stated in CEB-FIP [24],

$$
\begin{aligned}
& E_{0 d}=E_{0}\left(\frac{\dot{\varepsilon}}{\dot{\varepsilon}_{c o}}\right)^{0.026} \\
& f^{\prime}{ }_{c d}=f^{\prime}{ }_{c}\left(\frac{\dot{\varepsilon}}{\dot{\varepsilon}_{c o}}\right)^{1.016 \delta_{s}} \\
& {\varepsilon^{\prime}}^{\prime}=\varepsilon^{\prime}{ }_{c}\left(\frac{\dot{\varepsilon}}{\dot{\varepsilon}_{c o}}\right)^{0.02}
\end{aligned}
$$

where $E_{0 d}, f^{\prime}{ }_{c d}, \varepsilon^{\prime}{ }_{c d}, E_{0}, f^{\prime}{ }_{c}$ and $\varepsilon^{\prime}{ }_{c}$ represent the dynamic, static initial elastic modulus, compressive strength and the strain corresponding to the compressive strength respectively and $\dot{\varepsilon}_{c o}=3 \times 10^{-6} 1 / \mathrm{sec}$. The value of $\delta_{s}$ can be calculated as in equation (14)

$$
\delta_{s}=\frac{1}{10+6\left(f^{\prime}{ }_{c} / f c 0\right)}
$$

Where $f c 0=10 \mathrm{MPa}$.

Regarding steel modelling, reinforcement, rollers, and plates were simulated as elasticplastic material, ABAQUS/Explicit. The strain rate for reinforcement only using CowperSymonds model [25], is stated by:

$$
\sigma_{0}^{\prime}=\sigma_{0}\left[1+\left(\frac{\varepsilon^{*}}{D}\right)^{1 / q}\right]
$$

where $\sigma_{\mathrm{o}}{ }^{\prime}$ and $\dot{\varepsilon}$ are the dynamic flow stress and uniaxial plastic strain rate respectively. $\sigma_{\mathrm{o}}$ is the static flow stress, and D \& q are constants for a given material given us $40.4 \mathrm{sec}^{-1}$ and 5 respectively for mild steel [26].

\section{Sensitivity study}

In this section, the CPD input parameters are investigated whether they can establish the different $\mathrm{RC}$ beams under impact load. These parameters were the dilation angle, tensile damage models of concrete and the eccentricity.

\subsection{Dilation angle}

The sensitivity of the dilation angle has been studied against the experiment of Fujikake et al [8] that has been mentioned previously. To explore the effect of longitudinal reinforcement on the dilation angle's values, the three schemes of longitudinal reinforcements have been selected with impactor height of $1.2 \mathrm{~m}$, which were described in Section 2. 
In order to investigate the optimum value of dilation angle, several values were suggested comprised $30^{\circ}, 40^{\circ}, 50^{\circ}$ and $55^{\circ}$. The optimum values are selected based on the comparison of the displacement-time histories and failure patterns as shown in Fig. 6 to 9 .

It can be seen from Fig. 6 to 8 that the changing of the value of dilation angle can make a big change in the failure mode of a beam. For instance, when the value of dilation angle was $30 \mathrm{o}$, $40 \mathrm{o}$ and $45 \mathrm{o}$ for beam S1322 a continuous crack appeared in the line parallel to the longitudinal reinforcement. However, this crack was diminished when $\psi=50 \mathrm{o}$ and more shear cracks appeared in the beam making the crack pattern quite parallel to tested one. It was the same for the other beams when only one value for dilation angle can make the crack pattern similar to the experiment. Thus, it can be noticed from the same figures that the value of dilation angle for beams S1616, S1322 and S2222 are 45 o, 50 o and 50 o respectively. Consequently, the dilation angle depends on steel reinforcement of beam since the beams S1322 and S2222 had the same reinforcement ratio and dilation angle when the beam which had different reinforcement ratios had different dilation angles. Further simulations are made in this paper to confirm this conclusion.

Regarding the displacement-time history for beams, it can be seen from Fig. 9 that the dilation angle has a slight effect on the displacement-time history in most cases. In some cases and when $\psi=30 \mathrm{o}$, the value of maximum displacement was larger than or similar to the experimental results and other beams simulated with higher values of dilation angle exactly for beams S1616 and S2222. The reason for this is that for both beams and when $\psi=30$ o a wide flexural crack appeared in the beams caused this variation. However, these cracks were not observed in the experiment which makes these strange results. It should be mentioned here that in all cases and when the control value of dilation angle $(45 \mathrm{o}$ and $50 \mathrm{o}$ when $16 \mathrm{~mm}$ and $22 \mathrm{~mm}$ diameter bar were used in the tension zone) was used in the simulation there is a slight variation of data over time histories achieved from test and simulated results. These slight differences can be attributed to the support fixity where the perfect fixity of FE model does not exist in the experiment [27], [28].

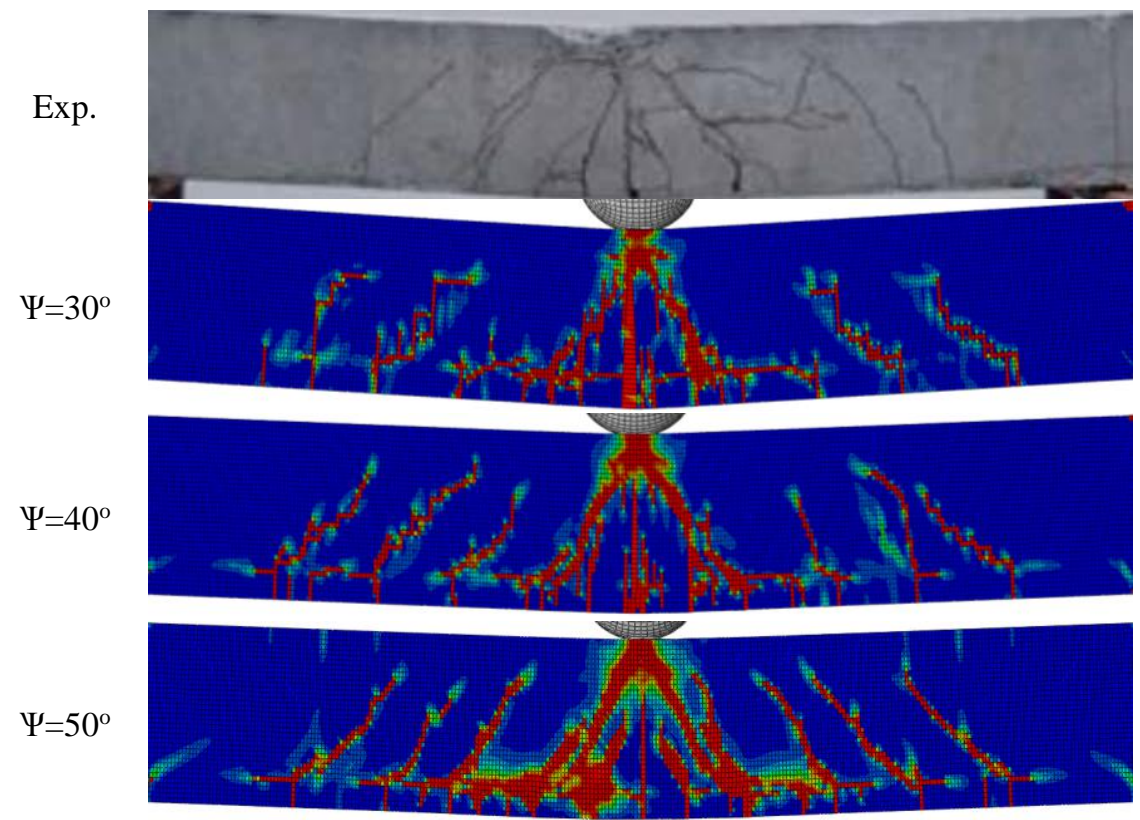




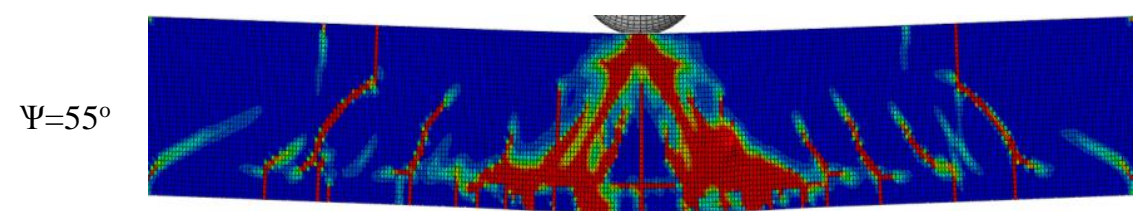

Fig. 6 Comparison of cracks patterns for beam S1616 (impact height $=1.2 \mathrm{~m}$ ) obtained from numerical results modelled with different values of dilation angle and experimental.

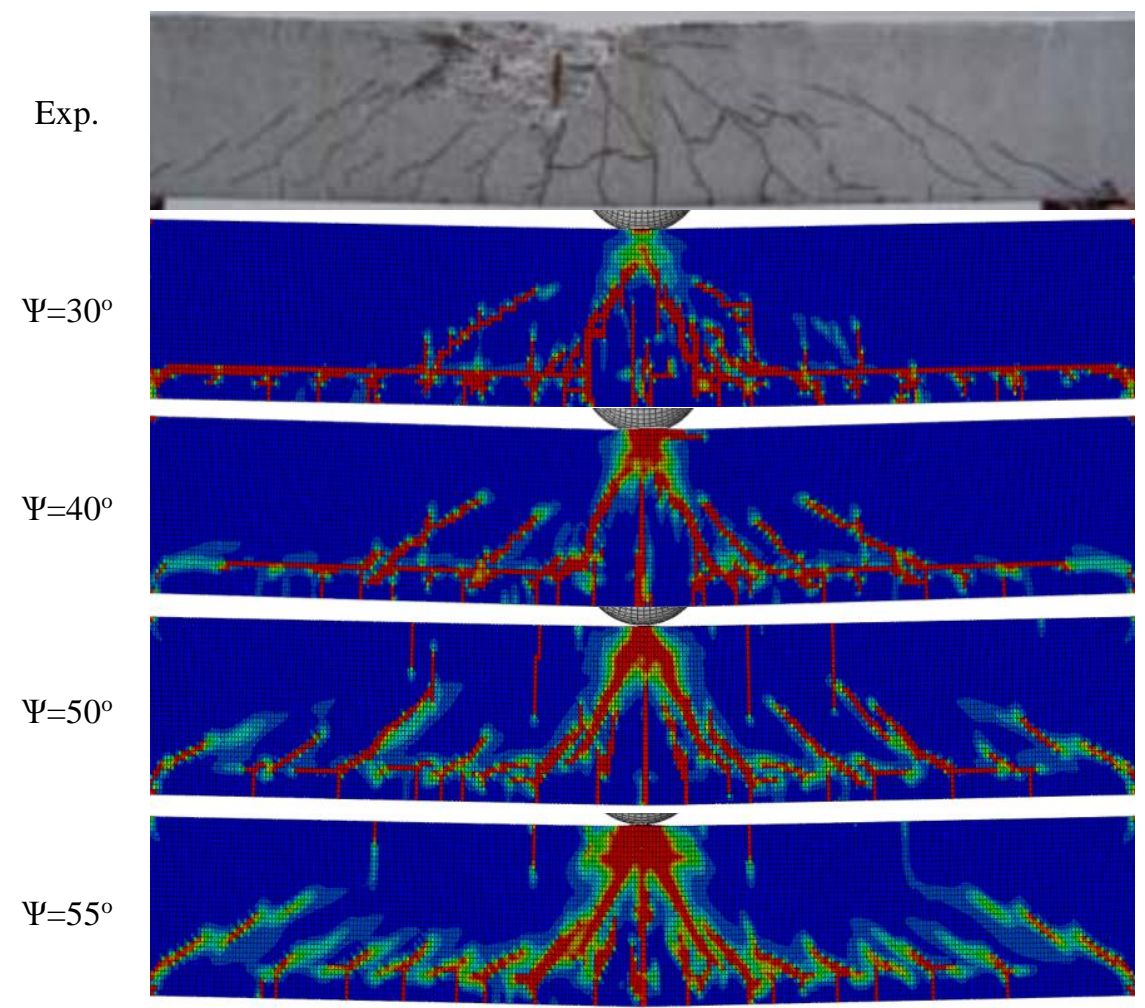

Fig. 7 Comparison of cracks patterns for beam S1322 (impact height $=1.2 \mathrm{~m}$ ) obtained from numerical results modelled with different values of dilation angle and experimental.

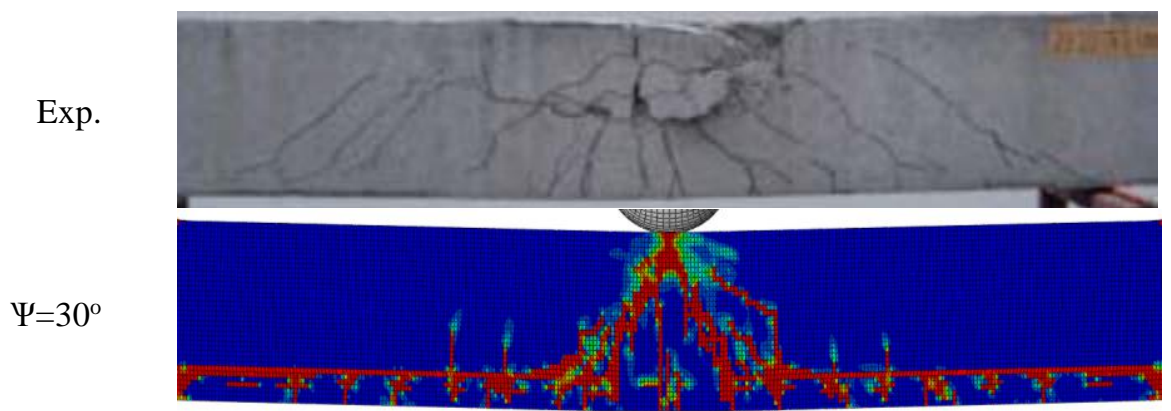



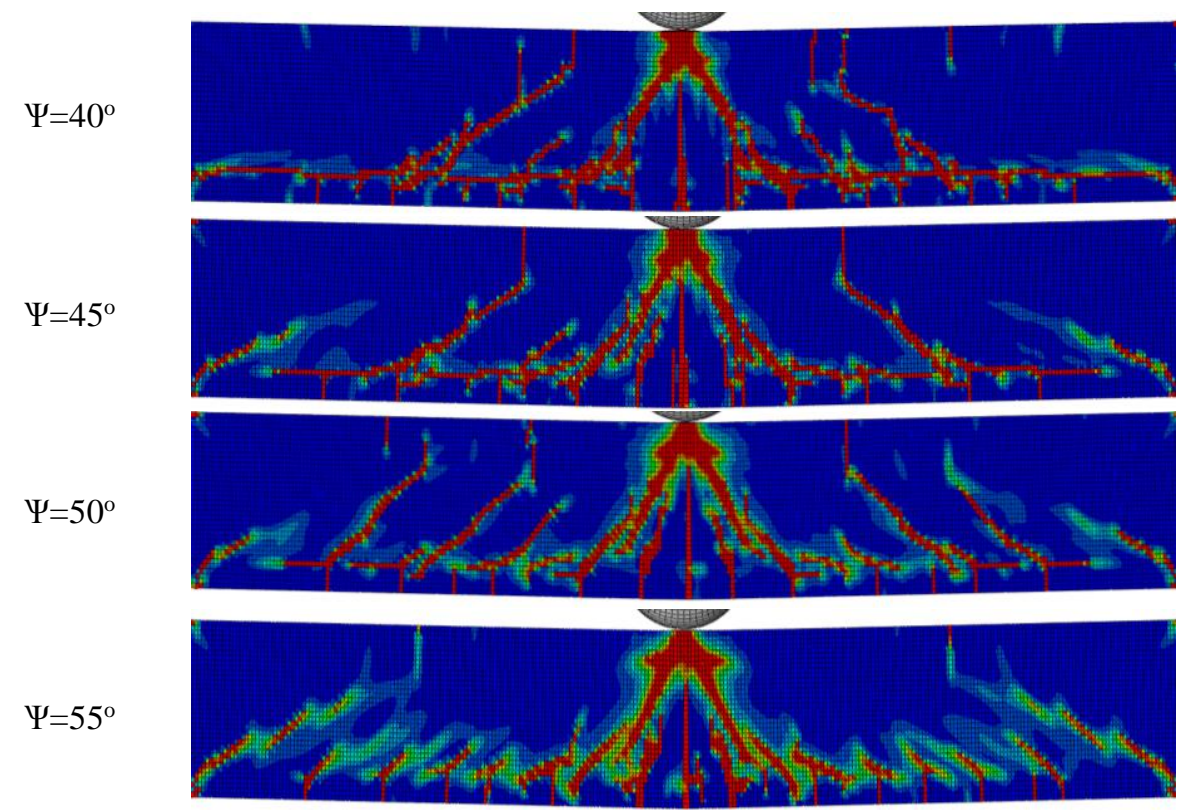

Fig. 8 Comparison of cracks patterns for beam S2222 (impact height $=1.2 \mathrm{~m}$ ) obtained from numerical results modelled with different values of dilation angle and experimental.

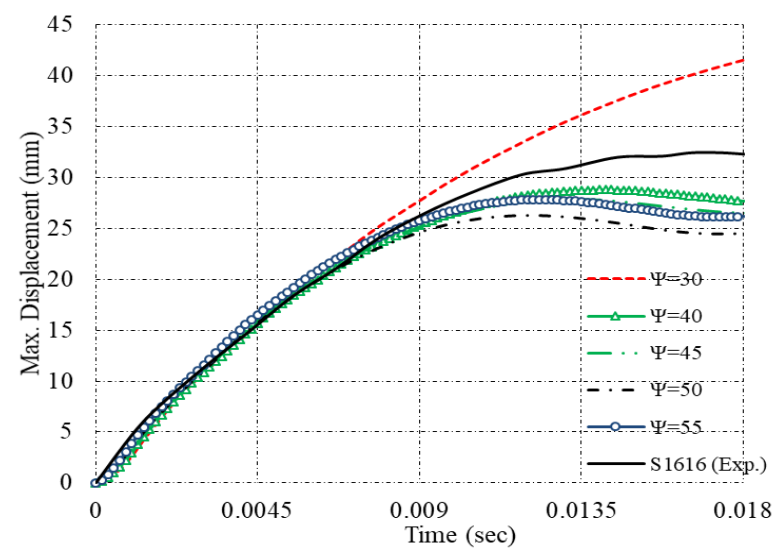


(a)S1616 reinforcement scheme

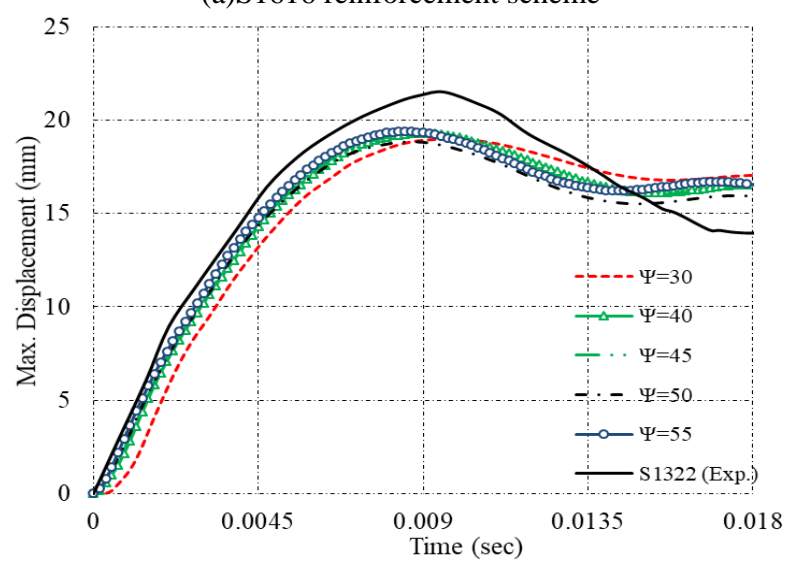

(b)S1322 reinforcement scheme

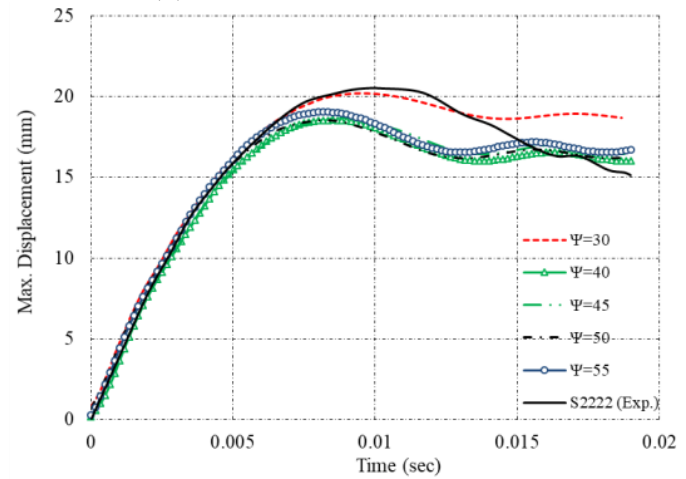

(c)S2222 reinforcement scheme

Fig. 9 Displacement-time histories of specimens S1616, S1322 and S2222 with different values of dilation angle

\subsection{Concrete damage model in tension}

In order to explore the sensitivity of the tensile model which is needed in implementing concrete damage plasticity, four models have been selected in modelling the concrete damage in tension as explained previously which are Models I to IV. Beam S1616 tested under $0.6 \mathrm{~m}$ impact height was used in this section. The cracks patterns of the beam obtained from experimental and numerical simulation which modelled with different concrete tensile models are presented in Fig. 10. It has noticed that the pattern of the cracks of Model I was significantly different from that gained from experimental testing. However and for other models, it seems that these models were able to capture the pattern of the cracks of the tested beam.

Exp.

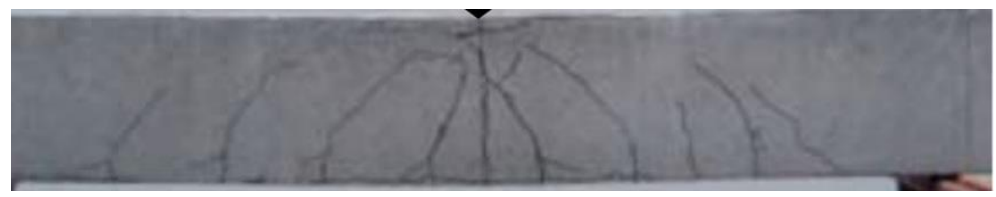



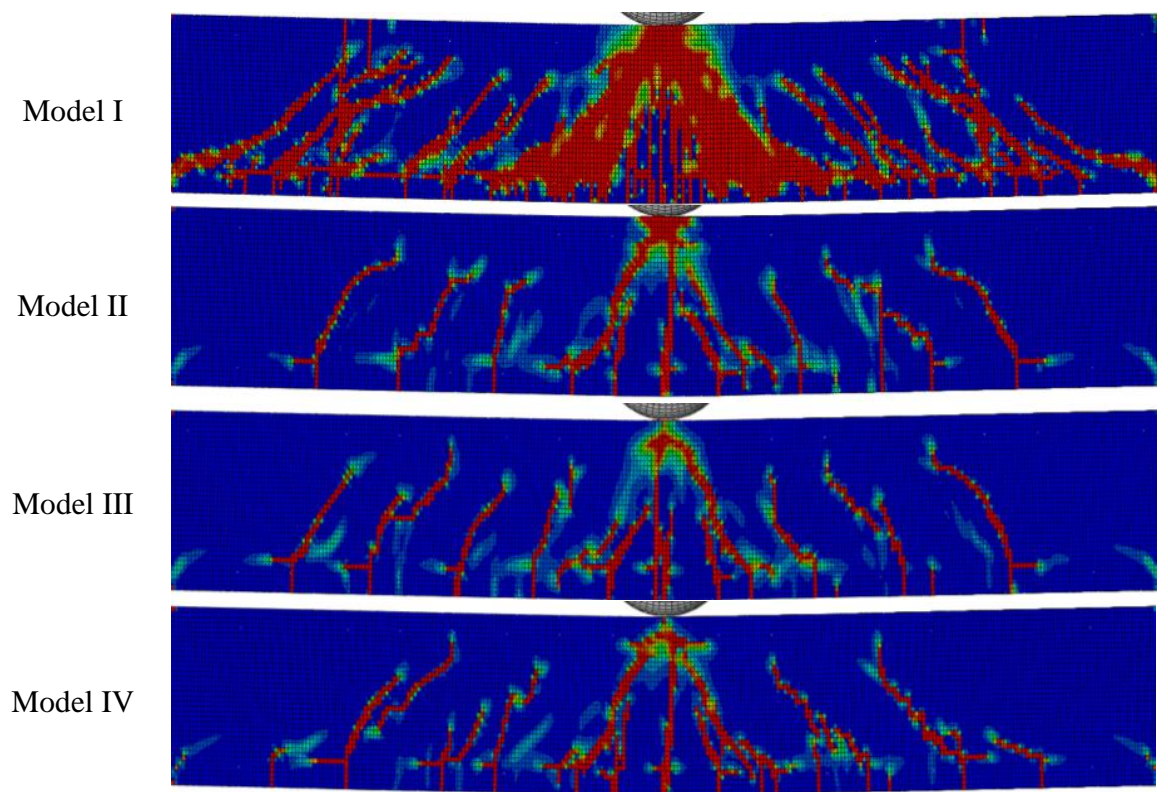

Fig. 10 Comparison of cracks patterns for beam S1616 (impact height $=0.6 \mathrm{~m}$ ) obtained from numerical results modelling with different concrete tensile model and experimental.

The maximum displacement-time history, see Fig. 11, showed that all models gave a good prediction for concrete damage in tension. However, there are slight differences between the numerical and experimental curves caused by the reason stated in Section 5.1. The comparison of impact force-time histories for experimental and numerical results is illustrated in Fig. 12; that all models provided a reasonable agreement with the experimental results. However, Model II provided the best convergence with the experimental curve apart from the impact time which was shorted compared to an experimental one.

Based on the aforementioned discussion, Model II has the best agreed results compared to the other models and so it will be used in the next simulations in this research.

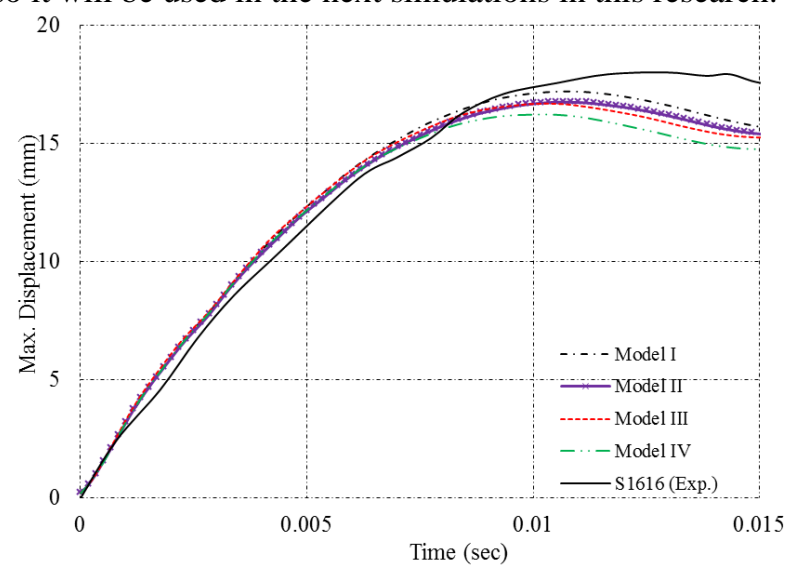

Fig. 11 Maximum displacement-time curves of specimen S1616 with different models of concrete damage in tension. 


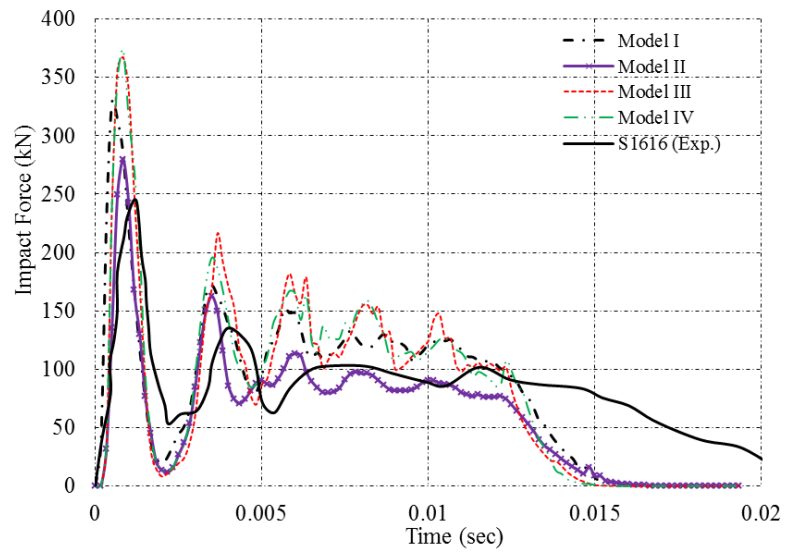

Fig. 12 Impact force-time relationship of specimen S1616 with different models of concrete tensile damage

\subsection{Eccentricity parameter}

This parameter is also needed in the modelling concrete damage plasticity. Many values have been used to investigate the proper value that can capture the concrete damage. Beam S1616 with impact height $1.2 \mathrm{~m}$ was used in this section. The comparison of the cracks patterns between experimental and numerical results for various values of eccentricity was plotted in Fig. 13. It is evident from this figure that the numerical model can capture the experimental cracks patterns in most cases. However, the accuracy of this model in capturing the pattern of the experimental cracks was better when $\mathrm{e}=0.10$ and 0.15 . Regarding the displacement-time history, it can be seen from Fig. 14 that all values of eccentricity provided a reasonable matched results with test results. Therefore, the eccentricity of 0.10 can be used in concrete damage modelling in the next validations since it is recommended by ABAQUS documentation [11].

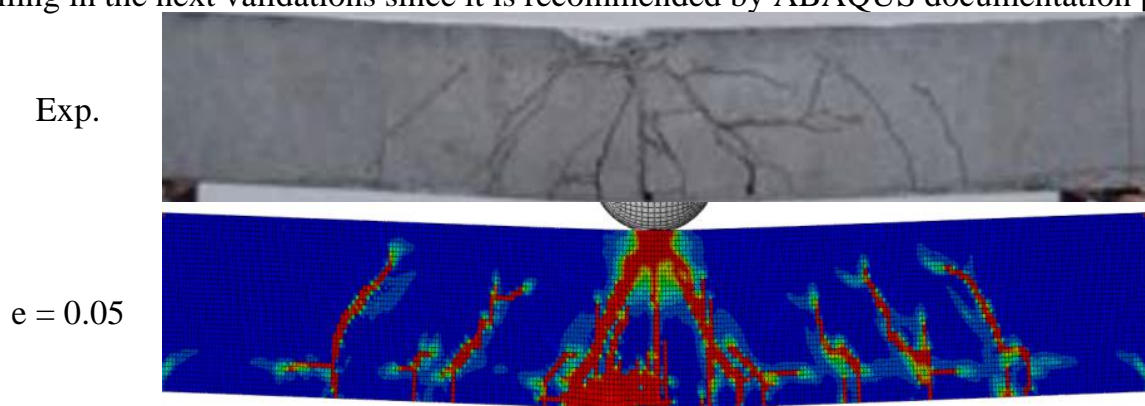

$\mathrm{e}=0.10$

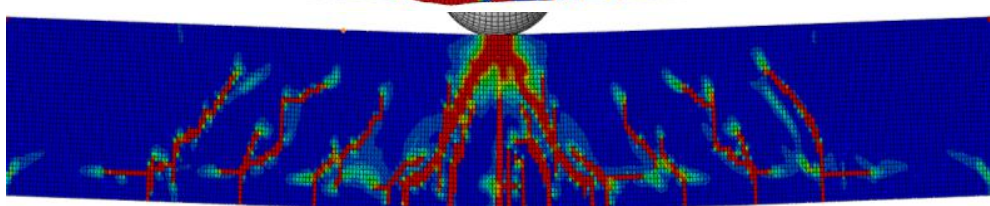

$\mathrm{e}=0.15$

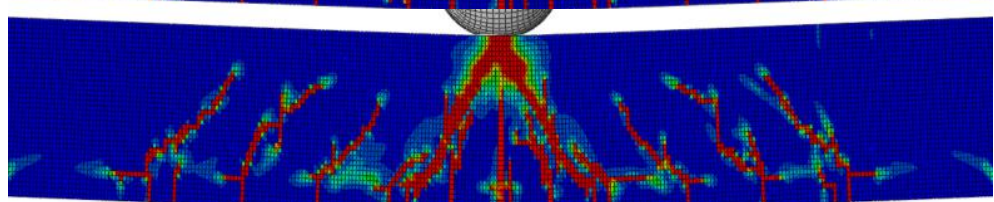




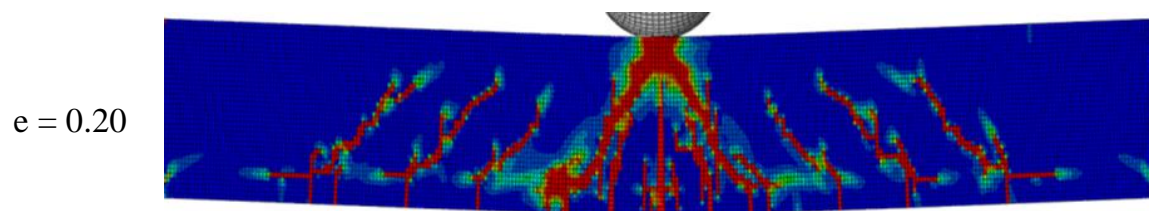

Fig. 13 Comparison of cracks patterns for beam S1616 (impact height = $1.2 \mathrm{~m}$ ) obtained from numerical results modelling with different eccentricity values and experimental.

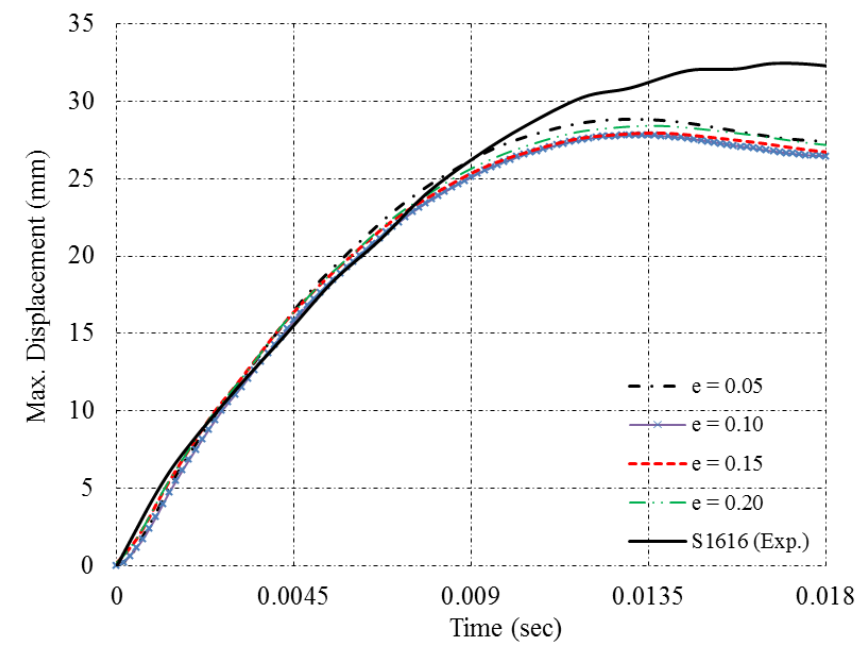

Fig. 14 Maximum displacement-time curves of specimen S1616 with different eccentricity values of concrete damage plasticity.

\section{Conclusions}

In this paper, the application of the concrete damage plasticity model for modelling the behaviour of concrete members subjected to high strain-rate was investigated. A special focus was put on the sensitivity of the model parameters (dilation angle, eccentricity, and the tensile damage models) on the analysis carried out. Based on the present results, we conclude:

- The value of the dilation angle has a significant influence on the failure model of the beam and linked with the steel reinforcement of the concrete beam. Also, it gives a good prediction for the beam behaviour when it ranged $45-50^{\circ}$.

- In terms of maximum displacement-time history and impact force-time histories, all models have been shown to provide an acceptable result, however, the trilinear model gives the closest result to the experimental curve.

- Although the displacement-time history is reasonably captured by applying all the values of the eccentricity parameter, however, the pattern of the cracks was captured with a good accuracy when a values of 0.10 and 0.15 is applied. Therefore, the recommended value of 0.1 by ABAQUS can be considered.

\section{References}


[1] Bhatti AQ, Kishi N, Mikami H, Ando T. Elasto-plastic impact response analysis of shearfailure-type RC beams with shear rebars. Mater Des 2009;30(3):502-10.

[2] Bhatti AQ, Kishi N, Konno H, Mikami H. Elasto-plastic dynamic response analysis of prototype RC girder under falling-weight impact loading considering mesh size effect. Struct Inf Eng 2010:1-11.

[3] Kishi N, Bhatti AQ. An equivalent fracture energy concept for nonlinear dynamic response analysis of prototype RC girders subjected to falling-weight impact loading. Int J Impact Eng 2010;37(1):103-13.

[4] Bhatti AQ, Kishi N. Impact response analysis of prototype RC girders with sand cushion using equivalent fracture energy concept. Int J DamageMech2011;20(3):1094-111.

[5] Thilakarathna HMI, Thambiratnam DP, Dhanasekar M, Perera N. Numerical simulation of axially loaded concrete columns under transverse impact andvulnerability assessment. Int $\mathbf{J}$ Impact Eng 2010;37(11):1100-12.

[6] H. Othman and H. Marzouk, "Applicability of damage plasticity constitutive model for ultrahigh performance fibre-reinforced concrete under impact loads,” Int. J. Impact Eng., vol. 114, November 2017, pp. 20-31, 2018.

[7] R. Shabbar, P. Nedwell, M. Al-Taee, Z Wu. Effect of Different Aluminium Powder Content on the Behaviour of Aerated Concrete: Experimental and Finite Element Validation International Journal of Materials, Mechanics and Manufacturing 6 (2), 155-158:2018.

[8] Kazunori Fujikake, Bing Li and Sam Soeun. Seismic response of composite shear connections. Journal of Structural Engineering, ASCE 2009,135:938-950.

[9] Lubliner J, Oliver J, Oller S, Onate E. A plastic-damage model for concrete. Solids Struct 1989;25:299-326.

[10] Lee J, Fenves G. Plastic-damage model for cyclic loading of concrete structures. Eng Mech 1998;124:892-900.

[11] Simulia. ABAQUS 6.14 user's manuals. Dassault Systèmes Simulia Corp 2016.

[12] Mousavi R, Champiri MD, Willam KJ. Efficiency of damage-plasticity models in capturing compaction-expansion transition of concrete under different compression loading conditions. 7th European congress on computational methods in applied sciences and engineering, Crete Island, Greece. 2016. p. 1-12.

[13] A. S. Genikomsou, M. A. Polak, "Finite element analysis of punching shear of concrete slabs using damaged plasticity model in ABAQUS, " Engineering Structures, vol. 98, pp. 38$48,2015$.

[14] T. Jankowiak, "Failure criteria for concrete under quasi-static and dynamic loadings," Poznan University of Technology Publishers, Poznan, 2011, (in Polish).

[15] T. Jankowiak, T. Lodygowski, "Identification of parameters of concrete damage plasticity costitutive model," Foundations of Civil and Environmental Engineering, 6, pp. 53-69, 2005.

[16] M. Szczecina, A. Winnicki, "Selected aspects of computer modeling of reinforced concrete structures," Archives of Civil Engineering, vol. LXII, Issue 1, pp. 51-64, 2016.

[17] M. A. Najafgholipour, S. M. Dehghan, A. Dooshabi, A. Niroomandi, "Finite Element Analysis of Reinforced Concrete Beam-Column Connections with Governing Joint Shear Failure Mode," Latin American Journal of Solids and Structures, vol. 14, pp. 1200-1225, 2017. [18] Y. T. Obaidat, "Structural retrofitting of concrete beams using FRP - Debonding Issues," Doctoral thesis, Lund University, Sweden, pp. 35-40, 2011.

[19] Kent D.C., Park R., 1971 "Flexural members with confined concrete." Journal of the Structural Division.

[20] ACI, 2014, Building code requirements for structural concrete (ACI 318-14) and commentary (ACI 318R-14). American Concrete Inst. 
[21] Nguyen H.T., Kim S.E., 2009, Finite element modelling of push-out tests for large stud shear connectors. Journal of Constructional Steel Research. 65: p. 1909-1920.

[22] Nayal, R., \& Rasheed, H.A. (2006). Tension Stiffening Model for Concrete Beams Reinforced with Steel and FRP Bars. Journal of Materials in Civil Engineering, 18(6), 831-84.

[23] Tao Y. and Chen J. F. (2015), Concrete Damage Plasticity Model for Modelling FRP-toConcrete Bond Behaviour. J. Compos. Constr. 19: p. 1909-1920.

[24] CEB-FIP. (1991). “CEB-FIP model code 1990.” Thomas Telford.

[25] Symonds P., Survey of methods of analysis for plastic deformation of structures under dynamic loading, 1967, Brown University Providence: No. BU/NSRDC/1-67.

[26] Jones N., 1997, Structural impact. Cambridge: Cambridge University Press.

[27] M.A. Kadhim, M. J. Altaee, A. H. Adheem, A. R. Jawdhari. A robust 3D finite element model for concrete columns confined by FRCM system. MATEC Web of Conferences, 281:2019.

[28] Zeinoddini, M., J. Harding, and G. Parke. 2008. “Axially pre-loaded steel tubes subjected to lateral impacts (a numerical simulation).” Int. J. Impact Eng. 35 (11): 1267-1279. 